\title{
Jurisprudência do Tribunal de Justiça da União Europeia sobre fiscalidade cooperativa: uma síntese crítica
}

\author{
The ECJ case law on taxation of cooperatives:
}

a critical summary

\author{
Nina Aguiar ${ }^{1}$ \\ Universidade do Porto (Portugal)
}

Sumário: 1. Introdução. 2. O regime dos auxílios de estado de natureza tributária no Tratado sobre o Funcionamento da União Europeia (TFUE). 2.1. Os requisitos necessários para se verificar a existência de uma ajuda de estado proibida. 2.2. Ajuda concedida pelo Estado em sentido amplo. 2.3. Tipos de medidas que constituem ajudas de estado. 2.4. A vantagem proporcionada às entidades beneficiárias da ajuda. 2.5. Melhoria da posição concorrencial. 2.6. Afectação do comércio intracomunitario. 3. Análise da jurisprudência do tribunal de justiça sobre a compatibilidade dos regimes fiscais das cooperativas com o regime europeu das ajudas de estado. 3.1. Sinopse da jurisprudência do Tribunal de Justiça em matéria de fiscalidade das cooperativas. 3.2. A questão da interdependência entre a tributação dos retornos dos excedentes cooperativos na pessoa dos sócios e a tributação dos resultados das cooperativas. 3.3. A questão da interdependência entre o regime fiscal favorável das cooperativas e as restrições impostas pelo regime cooperativo. 3.4. O argumento da justificação pela natureza e lógica do sistema. 3.5. A natureza não lucrativa das cooperativas como justificativa de um regime fiscal diferenciado. 3.6. A questão do quadro de referência. 3.7.A questão da comparabilidade entre as cooperativas e as sociedades comerciais. 4. Conclusão. 5. Bibliografia.

Summary: 1. Introduction. 2. The state aid rules under the Treaty on the Functioning of the European Union (TFUE). 2.1. The requirements necessary to verify the existence of a prohibited state aid. 2.2. Aid granted by the State in a broad sense. 2.3. Types of measures constituting state aid. 2.4. The advantage of the beneficiaries of the aid. 2.5. Improved competitive position. 2.6. Effect on intra-com-

1 Profesora titular de Derecho Tributário en el Instituto Politécnico de Bragança; Investigadora en el CIJE —Centro de Investigação Jurídico-Económica—; Faculdade de Direito da Universidade do Porto. Correo electrónico: naguiar@ipb.pt 
munity trade. 3. Analysis of the case law of the Court of Justice on the compatibility of the taxation of cooperatives with the European state aid rules. 3.1. Summary of the Court of Justice case law on taxation of cooperatives. 3.2. The interdependence between the taxation of patronage refunds by members and the taxation of cooperatives' income. 3.3. The interdependence between the favorable tax treatment of cooperatives and the legal restrictions imposed on cooperatives. 3.4. The justification of derogations on the basis of the nature and general scheme of the system. 3.5. The non-profit nature of cooperatives as a justification for a special tax regime. 3.6. The legal framework. 3.7. The comparability between cooperatives and commercial companies. 4. Conclusion. 5. Bibliography.

Resumen: Algunos países europeos, en los que se encuentra Portugal, tienen vigentes regímenes fiscales para las cooperativas que incluyen exenciones y minoraciones de varios impuestos. Por su carácter aparentemente beneficioso, estos regímenes han suscitado problemas relativos a su compatibilidad con el régimen de ayudas estatales de la Unión Europea y se espera que sigan suscitando. Hasta el momento presente, el Tribunal de Justicia dictó tres sentencias sobre esta temática. A pesar de ello el tema sigue enredado en muchas dudas e imprecisiones. Las decisiones y comunicaciones de la Comisión Europea, por su banda, son erráticas y conceptualmente inconsistentes. El presente artículo realiza una revisión de lo que pueden considerarse pautas resultantes de la jurisprudencia y de las cuestiones que quedan sin respuesta. cia.

Palabras-clave: Cooperativas; Fiscalidad; Ayudas de estado; jurispruden-

Abstract: Some European countries, including Portugal, have tax regimes for cooperatives that encompass exemptions and rebates from various taxes. As these traits look like tax incentives, these regimes have raised problems of compatibility with the European state aid rules and it is expectable that these problems continue to arise. Heretofore, the Court delivered three rulings on this subject. However the issue remains entangled in many doubts and inaccuracies. Decisions and communications from the European Commission, on the other hand, are erratic and conceptually inconsistent. This article makes a review of case law, searching for guidelines that may be considered set forth and identifying questions that remain unanswered.

Key words: Cooperatives; Taxation; State aid; Case law. 


\section{Introdução}

A complexa questão fiscal das cooperativas, no momento actual e no quadro dos estados membros da União Europeia, não pode deixar de ser equacionada à luz da problemática das ajudas de estado. Que assim é, provam-no as tomadas de posição da Comissão Europeia, através de sucessivas comunicações ${ }^{2}$ e decisões ${ }^{3}$ bem como a ainda escassa, mas assim mesmo significativa, jurisprudência do Tribunal de Justiça da União Europeia sobre a matéria, e que adiante se analisará.

Trata-se, além do mais, de uma questão de grande actualidade, uma vez que a Comissão Europeia tem em fase de consultas um projecto de comunicação sobre a noção de ajuda de estado que deverá incluir uma particular alusão às cooperativas, definindo as condições em que a fiscalidade das cooperativas pode ser diferenciada e mais favorável por comparação com a das sociedades. ${ }^{4}$

O princípio da proibição das ajudas de estado está consagrado actualmente no artigo 107(1) do Tratado sobre o Funcionamento da União Europeia (TFEU), mas faz parte do direito originário da Comunidade desde 1957, encontrando-se inicialmente consagrado no artigo 87 do Tratado que instituiu a Comunidade Económica Europeia (TCE). Pode considerar-se, portanto, um princípio estrutural do direito económico da União Europeia. ${ }^{5}$

Dispõe o actual artigo 107(1) do Tratado6: Salvo disposição em contrário dos Tratados, são incompatíveis com o mercado interno, na medida em que afectem as trocas comerciais entre os Estados-Membros, os auxílios concedidos pelos Estados ou provenientes de recursos

2 Cfr. Comissão Europeia, "Comunicação relativa à aplicação das normas sobre ajudas estatais às medidas relacionadas com a fiscalidade directa das empresas» [JO C 384 de 10.12.1998], parágrafo 25; e Comissão Europeia, "Comunicação da Comissão ao Conselho, ao Parlamento Europeu, ao Comité Económico e Social Europeu e ao Comité das Regiões relativa à promoção das cooperativas na Europa», [COM/2004/0018 final, 23.02.2004]; e Comissão Europeia, Communication from the Commission, Draft Commission Notice on the notion of State aid pursuant to Article 107(1) TFEU, Bruxelas, 2014, parágrafos 158 a 161.

3 Decisão da Comissão de 11 de Dezembro 2002 relativa às medidas executadas pela Espanha a favor do sector agrícola na sequência do aumento do preço dos combustíveis [notificada com o número C (2002) 4378], 2003/293/CE.

4 Comissão Europeia, Projecto de Comunicação da Comissão sobre a noção de auxílio estatal nos termos do artigo 107. ․, n. ${ }^{\circ}$ 1, do TFUE, Bruxelas, 2014.

5 Andrea Biondi e Martin Farley, "The relationship between the state aid and the single market», em Research Handbook on European State Aid Law, ed. por Erika Szyszczak (Temple: Edward Elgar Publishing, 2011), p. 277.

6 Artigo 87. ${ }^{\circ}$ do Tratado da Comunidade Europeia. 
estatais, independentemente da forma que assumam, que falseiem ou ameacem falsear a concorrência, favorecendo certas empresas ou certas produções.

Por força do princípio do primado do direito da União Europeia, o regime das ajudas de estado do artigo 107 do Tratado sobrepõe-se ao direito interno de cada Estado membro, incluindo as respectivas constituições. $^{7}$

Mas o princípio da proibição das ajudas de Estado não determina automaticamente a incompatibilidade de qualquer regime de benefícios fiscais ou de qualquer regime fiscal diferenciado que possa ser considerado mais favorável em comparação com um regime de referência. A fim de que, em virtude da aplicação do princípio da proibição das ajudas de estado do artigo 107(1) do TFEU, um determinado regime jurídico seja considerado incompatível com o direito europeu da concorrência, é necessário verificar que se preenche uma série de requisitos. ${ }^{8} 9$

A dificuldade da questão, patentemente actual, da fiscalidade das cooperativas no contexto europeu e, ao mesmo tempo, o seu interesse do ponto de vista académico, decorrem de ser bastante discutível a verificação dos referidos requisitos de aplicação do princípio em relação ao regime fiscal das cooperativas em geral, sendo que a dificuldade da questão aumenta com a complexidade e variedade da realidade cooperativa, do ponto de vista quer económico quer jurídico. ${ }^{10}$

A questão da aplicabilidade, em abstracto, do regime das ajudas de estado a entidades com a natureza de cooperativas não oferece na actualidade sérias dúvidas. ${ }^{11}$ Como melhor veremos adiante, as cooperati-

7 Sobre o princípio do primado vd. Robert Schütze, An Introduction to European Law (Cambridge: Cambridge University Press, 2015), p. 150. O princípio foi estabelecido pela pri vez pelo Tribunal de Justiça no caso 6/64 Costa v Enel, [1964] ECR 585.

8 Juan Jorge Piernas López, The Concept of State Aid Under EU Law: From internal market to competition and beyond (Oxford: Oxford University Press, 2015), pp. 67 et seq.; Vittorio di Bucci, "Direct taxation - State aid in form of fiscal measures», em The EC State Aid Regime: Distortive Effects of State Aid on Competition Trade, ed. por Michael Sánchez Rydelski, (Londres: Cameron May, 2006), pp. 73 et seq.

9 Vd. acórdãos do TJUE nos processos C-39/14, BVVG, de 16 de Julho de 2015 (ainda não publicado); T-34/02, SUQ Le Levant 001, de 22 de Fevereiro de 2006, Col. de Jur. [2010] II-06375.

10 Conclusões do Advogado-Geral Niilo Jääskinen nos processos apensos C-78/08 a C-80/08, Paint Graphos e Outros, parágrafo 46.

11 Comissão Europeia, Communication from the Commission, Draft ,... cit., parágrafos 158 a 161. Emmanuele Cusa, "State aid law and cooperatives in Europe», em Genossenschaften im Fokus einer neuen Wirtschaftspolitik: Bericht der XVII. Internationalen Genossenschaftswissenschaftlichen Tagung (IGT) 2012 in Wien, Parte 1, ed. por Johann Brazda, Markus Dellinger e Dietmar Rossl (Munique:LIT, 2013), p. 1109. 
vas são entidades empresariais para efeitos do direito europeu da concorrência, tanto bastando para que sejam abrangidas pelo respectivo regime. Mas já a questão de saber se um regime fiscal preferencial para as cooperativas, em concreto, será incompatível com o regime dos auxílios de estado estabelecido no artigo 107(1) do TFEU continua a ser debatida. Esta é uma questão que se encontra em aberto e sobre a qual se têm registado alguns avanços, nem sempre consistentes, sobretudo no que respeita à posição da Comissão Europeia sobre a matéria. ${ }^{12}$

O foco essencial deste artigo será uma análise e um ponto de situação relativos às condições que, de acordo com a jurisprudência do Tribunal de Justiça da União Europeia, é necessário verificarem-se para que um regime fiscal cooperativo diferenciado possa ser considerado compatível com o direito da União Europeia. Primente, porém, a fim de dar ao tema o devido enquadramento, proceder-se-á a uma revisão do conceito de ajuda de estado de natureza fiscal.

Sobre o tema principal que aqui nos ocupa, a jurisprudência do TJUE sobre a fiscalidade das cooperativas, existem já alguns estudos publicados de grande relevo. Referimo-nos, em particular, aos estudos de Pilar Alguacil, ${ }^{13}$ Merino Jara ${ }^{14}$ Cusa $^{15}$ e Azcoaga Ibarra, ${ }^{16}$ entre outros de âmbito mais restrito. ${ }^{17} \mathrm{~A}$ presente reflexão é tributária de todos

12 Juan José Hinojosa Torralvo, «Fiscalidad y financiación de las cooperativas: ¿a qué juega la Unión Europea?», CIRIEC-España: Revista de Economía Pública, Social y Cooperativa, $n .{ }^{\circ} 69$ (2010), p. 78.

13 Maria Pilar Alguacil: «Tax treatment of cooperatives in Europe under state aid rules», em Genossenschaften im Fokus einer neuen Wirtschaftspolitik: Bericht der XVII. Internationalen Genossenschaftswissenschaftlichen Tagung (IGT) 2012 in Wien, Parte 1, ed. por Johann Brazda, Markus Dellinger e Dietmar Rossl (Munique:LIT, 2013), 1091-1104; "Condicionantes el régimen de ayudas de estado en la fiscalidade de cooperativas», ClRIEC-España: Revista de Economía Pública, Social y Cooperativa, n. ${ }^{\circ} 69$ (2010), 27-52.

14 Isac Merino Jara: «El régimen fiscal de las cooperativas ¿respeta el régimen comunitario de ayudas de estado?», GEZKI-Revista Vasca de Economía Social, n. ${ }^{\circ} 6$ (2010), 29 57; "El vigente régimen fiscal de las cooperativas a la luz de las ayudas de Estado», ClRIEC-España, Revista de Economía Pública, Social y Cooperativa, n. ${ }^{\circ} 66$ (2009), 109-126.

15 Emmanuele Cusa, op. cit, pp. 1105-1120.

16 Mikel Azcoaga Ibarra, "Tax treatment of cooperatives and EU State aid policy», Revista Vasca de Economía Social, n. ${ }^{\circ} 11$ (2014), 103-142.

17 Marco Antonio Rodrigo Ruiz, "Consideraciones sobre el régimen fiscal de las cooperativas. Problemas actuales y líneas de reforma», CIRIEC-España: Revista de Economía Pública, Social y Cooperativa, n. 69 (2010), 9-25; José Manuel Tejerizo López, "Algunas reflexiones sobre el régimen fiscal de las cooperativas», CIRIEC-España: Revista de Economía Pública, Social y Cooperativa, n. 69 (2010), 53-72; Juan José Hinojosa Torralvo, op. cit., pp. 73-89; Agustín Romero Civera, A. "La fiscalidad aplicada a cooperativas en Europa y la reforma del régimen fiscal en España», CIRIEC-España: Revista de Economía Pública, Social y Cooperativa, n. ${ }^{\circ} 69$ (2010), 91-118. 
estes valiosos contributos prévios. Consideramos, sem embargo, que existem ainda aspectos que é pertinente explorar e aprofundar, tendo em conta que países como Portugal, onde existe um regime fiscal cooperativo que contempla diversas isenções mas que, no entanto, se mostra obsoleto e ineficiente do ponto de vista da sua aplicabilidade, ${ }^{18}$ necessitam urgentemente de reformular o regime fiscal aplicável às cooperativas, mas devendo fazê-lo em conformidade com o direito europeu.

\section{O regime dos auxílios de estado de natureza tributária no Tratado sobre o Funcionamento da União Europeia (TFUE)}

\subsection{Os requisitos necessários para se verificar a existência de uma ajuda de estado proibida}

Segundo o artigo 107(1) do Tratado "são incompatíveis com o mercado interno, na medida em que afectem as trocas comerciais entre os Estados-Membros, os auxílios concedidos pelos Estados ou provenientes de recursos estatais, independentemente da forma que assumam, que falseiem ou ameacem falsear a concorrência, favorecendo certas empresas ou certas produções.»

Daqui se infere de imediato que nem todas as ajudas públicas são automaticamente incompatíveis com o mercado interno, mas que uma ajuda pública só será incompatível com o mercado interno, i.e. com o direito da União Europeia, se se verificarem simultaneamente vários pressupostos (tests). ${ }^{19} 20$ Esses pressupostos são:21

- A ajuda deve ser concedida pelo Estado (em sentido lato) ou através de recursos do Estado;

- A ajuda deve ser de modo a conferir uma vantagem competitiva ao seu receptor;

18 Nina Aguiar, "A tributação do rendimento das cooperativas em Portugal», RCESRevista Cooperativismo y Economía Social, n. ${ }^{\circ} 36$ (2013/2014), 55-80..

19 Phedon Nicolaides, Mihalis Kekelekis e Philip Buyskes, State Aid Policy in the European Community: A Guide for Practitioners (Kluwer Law International, 2005), p. 10; A. Biondi "Some reflections on the notion of «state resources»in European Community state aid law», Fordham International Law Journal, vol. 30, n. ${ }^{\circ} 5$ (2006), p. 1428. TJUE, acórdão de 6 de Março de 2015, caso C-667/13, Banco Privado Português, não publicado, parágrafo 45 e jurisprudência citada.

20 TJUE, acórdão no processo C-39/14 BVVG, de 16 de Julho de 2015 (ainda não publicado) e a jurisprudência aí citada.

21 Phedon Nicolaides, Mihalis Kekelekis e Philip Buyskes, op. cit., p. 10. 
- A vantagem deve favorecer certas empresas ou certas «produções»;

- A ajuda deve afectar o comércio entre Estados Membros; e

- A ajuda deve distorcer a concorrência no mercado interno.

\subsection{Ajuda concedida pelo Estado em sentido amplo}

O primeiro pressuposto da existência de uma ajuda de estado diz respeito à origem da ajuda. O artigo 107(1) proíbe, nas condições aí referias, os auxílios concedidos pelos Estados ou provenientes de recursos estatais.

O Tribunal de Justiça tem entendido o termo «estado» em sentido amplo. ${ }^{22}$ Conforme jurisprudência firme do Tribunal, cabem no conceito tanto as ajudas outorgadas pelo Estado enquanto pessoa colectiva de direito administrativo, como as outorgadas por meio de um organismo público ou privado designado ou instituído pelo Estado, ${ }^{23}$ ou ainda por um ente público territorial infra estatal. ${ }^{24}$

\subsection{Tipos de medidas que constituem ajudas de estado}

No que se refere ao tipo de medidas que podem constituir ajudas de estado, o Tribunal de Justiça tem vindo a construir igualmente um conceito amplo de ajuda estatal. Como observa BIONDI, ${ }^{25}$ o Tribunal tem feito uma interpretação extensiva do conceito, segundo a qual «ajuda e estado» é "qualquer medida que confira uma vantagem económica a uma empresa ou sector e que seja o resultado de uma conduta atribuível ao Estado.» Incluem- se no conceito, desde logo, as medidas que impliquem «prestações positivas» ou seja prestações públicas que provoquem uma transferência efectiva, actual ou futura de fundos estatais, como as subvenções, que implicam uma saída efectiva e actual de fundos públicos. ${ }^{26}$ Cabem ainda no conceito outras formas de

22 Magnus Schmauch, EU Law on State Aid on Airlines: Law, Economics and Policy (Berlim: Lexxion Verlagsgesellschaft, 2013), p. 88.

23 TJUE, caso C-222/07, Preussen Elektra, ECR, 5 de Março de 2009, [2009] I-01407, parágrafo 58.

24 TJUE, caso C-248/84, Alemania/Comissão, 14 de Outubro de 1987, ECR [1987] 1-4013.

25 Andrea Biondi., Some reflections..., cit., p. 1432.

26 TJUE, caso T-369/06, Holland Malt, 9 de Setembro de 2009, [2009] II-03313. 
prestações positivas como empréstimos ${ }^{27}$ ou tomadas de participação no capital das empresas. ${ }^{28}$

Mas também se incluem no conceito medidas que provoquem não uma saída efetiva e atual de fundos públicos mas um risco económico «suficientemente concreto» de encargos futuros que onerem o orçamento do estado ${ }^{29}$ ou uma diminuição dos ingressos públicos potenciais. ${ }^{30} \mathrm{Na}$ pri hipótese enquadrar-se-iam situações como a concessão de uma garantia de Estado, ${ }^{31}$ ou até o anúncio de um compromisso público de antecipação de accionista. ${ }^{32} \mathrm{Na}$ segunda hipótese cabem situações em que o ente público renuncia a cobrar receitas que deveria poder arrecadar em condições normais, como quando vende um bem a um operador económico por um preço abaixo do valor de mercado. ${ }^{33}$ Nesta hipótese cabem também os benefícios fiscais ou os perdões fiscais, que nos interessam em particular para o tema que aqui nos ocupa. ${ }^{34}$

Por outro lado, a despesa pública com o sentido amplo mencionado anteriormente pode ser ou não ser individualizada. Apesar de não existir ainda jurisprudência do TJUE que firme este entendimento, existe uma evolução no sentido de incluir no conceito de ajuda estatal as despesas com infra-estruturas de uso colectivo que beneficiam apenas certas empresas ou grupos de empresas, e quando o Estado ou outro ente público não cobre uma taxa de utilização. Tal como ficou claro no caso Eventech, ${ }^{35}$ o primeiro caso em que se pediu ao tribunal que aplicasse o conceito de ajuda de Estado em relação a uma despesa pública em infra-estruturas de uso colectivo, a não qualificação destes gastos como ajuda de Estado proibida depende unicamente de se demonstrar que o tratamento diferenciado não causa uma vantagem

27 TJUE, caso C-409/00, Reino de España /Comissão, 13 de Fevereiro de 2003, [2003] I-01487.

28 TJUE, caso T-156/04, EDF, 15 de Dezembro de 2009, [2009] II-04503.

29 TJUE, casos acumulados C-399/10 P y C-401/10 P, Bouygues e Bouygues Télécom, 19 de Março de 2013 [2013] ECR I-0000], parágrafo 109.

30 TJUE, caso C-73/03, Reino de España/Comissão, 11 de Novembro de 2004 (ainda não publicado); TJUE, caso C-251/97, Francia/Comissão, 5 de Outubro de 1999, [1999] I-06639, parágrafo 35.

31 TJUE, caso C-200/97, Ecotrade, 1 de Dezembro de 1998, [1998] I-07907 parágrafo 43; TJUE, caso C-275/10, Residex Capital IV, 8 de Dezembro de 2011, [2011] I-13043, parágrafos 39 a 42. 28

32 Sentença Bouygues e Bouygues Télécom (C-399/10 P y C-401/10 P), supra, nota

33 TJUE, caso C-39/14, BVVG Bodenverwertungs, 16 de Julho de 2015 (ainda não publicada).

34 Sentença Reino de España/Comissão, caso C-73/03, supra, nota 29.

35 TJUE, caso C-518/13, Eventech, de 14 de Janeiro de 2015, (ainda não publicada). 
competitiva. ${ }^{36}$ Outro caso em que se colocou uma questão em termos parecidos foi o caso Gemo, ${ }^{37}$ em que o Tribunal considerou como ajuda de Estado um regime vigente em França que garantia aos ganadeiros e aos matadouros a recolha e a eliminação gratuitas de animais mortos e de detritos de matadouro.

\subsection{A vantagem proporcionada às entidades beneficiárias da ajuda}

O terceiro elemento a distinguir no conceito de ajuda de estado proibida é o que respeita aos efeitos económicos produzidos pela intervenção pública nas entidades beneficiadas. Enquanto as ajudas que consistem em transferências directas de fundos públicos para as entidades empresariais, como as subvenções, originam um enriquecimento efectivo destas entidades, outros tipos de ajudas, como precisamente os benefícios fiscais, colocam os beneficiários numa situação financeira mais favorável, 38 ao reduzir os custos que normalmente recairiam sobre elas. ${ }^{39}$ O Tribunal fala neste caso de «vantagens indirectas» e dá como exemplos deste tipo de vantagens o fornecimento de bens e a prestação de serviços em condições preferenciais. ${ }^{40} \mathrm{Em}$ qualquer dos casos, a intervenção pública coloca a empresa ou grupo de empresas beneficiárias numa situação económica mais favorável por comparação com a situação que existiria não fora essa mesma intervenção pública. Em

36 Nas suas conclusões no caso Eventech, C-518/13, supra, nota 34, o AdvogadoGeral Wahl observa que "ao regular o acesso às infraestruturas, o Estado tem obviamente de agir numa qualidade regulatória genuína, o que implica regular situações comparáveis do mesmo modo, para que a concorrência não seja falseada. Com efeito, o facto de uma infraestrutura ser colocada à disposição de todos os utilizadores numa base equitativa e não discriminatória é um indício de que não foi concedido qualquer auxílio a esses utilizadores. Em contrapartida, se, por exemplo, o Estado cobrar habitualmente pelo acesso a infraestruturas públicas (como a portagem cobrada pela utilização de uma autoestrada pública) ou a outros recursos do domínio público, mas conceder acesso gratuito discricionariamente a diversas empresas, poderá estar a renunciar a receitas em relação a essas empresas» (parágrafo 32).

37 TJUE, caso C-126/01, Gemo, 20 de Novembro de 2003, [2003] I-13769.

38 TJUE, caso C-105/14, Taricco, 8 de Setembro de 2015, (ainda não publicado) parágrafo 61 .

39 TJUE, caso C-690/13, Trapeza Eurobank Ergasias, 16 de Abril de 2015 (ainda não publicado) parágrafo 21; TJUE, caso C-522/13, Navantia, 9 de Outubro de 2014, (ainda não publicado) parágrafo 22; Bouygues e Bouygues Télécom (C-399/10 P y C-401/10 P), supra nota 28, parágrafo 101.

40 TJUE, caso C-276/02, Espanha/Comissão, 14 de Setembro de 2004, [2004] I-08091, parágrafo 24; TJUE, casos C-341/06 P y C-342/06 P, Chronopost y La Poste/ UFEX, 1 de Julho de 2008, [2008] I-04777, parágrafo 123. 
algumas ocasiões, o Tribunal lançou mão do conceito de «condições normais de mercado» para averiguar se a medida pública origina una vantagem para os seus beneficiários. ${ }^{41}$ Neste sentido, poderá considerar-se a medida como favorecendo una empresa ou sector empresarial quando lhes proporcione uma vantagem de que não beneficiariam em condições normais de mercado. Em conclusão, o conceito de ajuda de Estado, no que respeita ao tipo de medida, abrange formas muito variáveis, sendo essencial ao conceito que a medida proporcione uma vantagem económica a algum ou alguns operadores económicos de que não beneficiariam não fora a medida do ente público. ${ }^{42}$

\subsection{Melhoria da posição concorrencial}

\subsubsection{O CARÁCTER SELECTIVO DA MEDIDA}

Referindo-nos ainda ao efeito económico da intervenção pública, e centrando-nos agora mais em particular no plano da concorrência, a intervenção estatal deve ter como consequência uma melhoria da posição concorrencial da entidade ou entidades beneficiárias da medida ${ }^{43}$ o que requere avaliar os efeitos da medida pública em termos comparativos. Este efeito no plano concorrencial produz-se automaticamente quando à vantagem económica já referida —enriquecimento ou alívio dos custos que normalmente recairiam sobre a entidade ou ainda qualquer outra melhoria das condições económicas dos beneficiados- se soma o carácter selectivo da vantagem concedida. ${ }^{44} \mathrm{Na}$ sentença sobre o caso Alemanha/Comissão ${ }^{45}$ o Tribunal declarou que «em princípio, as ajudas ao funcionamento, ie aquelas que (...) têm como objectivo desonerar uma empresa dos custos próprios da sua gestão corrente ou das suas actividades normais, que em condições normais deveria suportar, falseiam as condições de concorrência». Deste modo, considera-se que, por princípio, qualquer medida que desonere uma empresa dos encargos financeiros normais, à custa de uma diminuição de fundos

41 TJUE, caso C-280/00, Altmark Trans y Regierungspräsidium Magdeburg, 24 de Julho de 2003, [2003] I-07747, parágrafo 84.

42 Michael Schütte, «The notion of state aid», em The EC State Aid Regime: Distortive Effects of State Aid on Competition Trade, ed. por Michael Sanchez Rydelski (Londres: Cameron May, 2006), p. 29.

43 Phedon Nicolaides, Mihalis Kekelekis e Philip Buyskes, op. cit., p. 17.

44 TJUE, caso C-403/10 P, Mediaset, 28 de Julho de 2011, [2011] I-00117; TJUE, caso C-156/98, Alemanha/ Comissão, 19 de Setembro de 2000 [2000] 1-06857.

45 Alemanhal Comissão (C-156/98), supra nota 43, par. 30. 
públicos, é susceptível de afectar a concorrência, desde que reforce a posição de uma empresa em relação a outras empresas concorrentes, ou seja desde que a medida seja selectiva. ${ }^{46}$

O requisito do carácter selectivo da medida qualificada como ajuda de Estado resulta do estipulado no Art. 107(1) do TFUE, na parte em que se refere a «ajudas que favoreçam determinadas empresas ou produções». O carácter selectivo da medida é, por conseguinte, um dos elementos do conceito jurídico de ajuda estatal. ${ }^{47}$ É aí, contudo, que se encontram as maiores dificuldades do conceito. ${ }^{48}$

Uma interpretação possível e simplista do critério seria que uma ajuda estatal é selectiva quando é selectiva na sua formulação, dirigindo-se a determinadas empresas ou produções e deixando de fora outras empresas ou produções. O TJUE empregou o critério com este sentido em vários casos, como por exemplo na sentença Itália/ Comissão, ${ }^{49} \mathrm{em}$ que o Tribunal afirmou que "as vantagens resultantes de uma medida geral aplicável sem distinção a todos os operadores económicos não constituem ajudas de Estado no sentido do artigo 107(1).»50 Não obstante, o Tribunal também admitiu em várias ocasiões que a medida pode ser desenhada de tal maneira que, ainda que formulada em termos de aplicação geral a todas as empresas ou produções, em última instância beneficiará apenas algumas dessas empresas ou alguns desses sectores. ${ }^{51} 52$ Reconhecendo este facto, o Tribunal de Justiça tem afirmado reiteradamente que o critério de selectividade se mede pelos efeitos que a medida produz, independentemente dos seus objectivos. ${ }^{53}$ Por exemplo, o facto de uma medida se aplicar a todo um sector económico não é razão suficiente para con-

46 Ibidem.

47 Segundo o TJUE, na sua decisão nos procesos acumulados C-106/09 P y C-107/09 P, Comissão Europeia/Governo de Gibraltar, de 15 de Novembro de 2011, "a selectividade é constitutiva do conceito de auxílio de Estado».

48 Sobre o conceito de selectividade Juan Jorge Piernas López, op. cit., pp. 117 et seq.

49 TJUE, assunto C-66/02, Itália/Comissão, 15 de Dezembro de 2005, [2005] I-10901.

50 Itália/Comissão (C-66/02), parágrafo 99. O TJUE enuncia o critério com este sentido na sentença Trapeza Eurobank Ergasias (C-690/13).

51 Gemo (C-126/01).

52 Christian Ahlborn e Claudia Berg, "Can aid state control learn from antitrust? The need for a greater role for competition analysis under the sate aid rules», em The Law of State Aid in the European Union, ed. por Andrea Biondi, Piet Eeckhout, and James Flynn (Oxford: Oxford University Press, 2004), p. 51.

53 TJUE, caso C-56/93, Bélgica/Comissão, 29 de Fevereiro de 1996, [1996] I-00723, parágrafo 79; TJUE, caso C-241/94, França/Comissão, 26 de Setembro de 1996, [1996] 1-4551, parágrafo 20. 
cluir que não se trata de una medida discriminatória, e portanto selectiva, em termos concorrenciais. ${ }^{54}$

\subsubsection{O REQUISITO DE COMPARABILIDADE}

Por outro lado, o carácter selectivo da medida significa uma diferenciação, o que implica que só pode verificar-se em relação a um universo de empresas ou produções que estejam numa situação factual e jurídica comparável. ${ }^{55}$ Assim, em termos gerais, o carácter selectivo de uma medida pública existirá quando esta medida origine una vantagem competitiva para certas empresas ou produções em relação a outras empresas ou outros sectores que se encontrem numa situação fáctica e jurídica comparável aos primeiros. ${ }^{56}$ Todavia, a questão do parâmetro para verificar a comparabilidade entre as empresas beneficiarias e as que não beneficiam da medida é complexa e é, de todos os requisitos do critério da selectividade, o que maiores problemas suscita. ${ }^{57}$

O requisito da comparabilidade constitui um elemento central na problemática da compatibilidade dos benefícios fiscais cooperativos com o regime das ajudas de Estado.

De acordo com a jurisprudência do TJUE, a comparabilidade entre as entidades afectadas - entre as entidades que são beneficiadas e as que não são beneficiadas, entenda-se- deve ser aferida em função dos objetivos da legislação aplicável. ${ }^{58}$ Mas neste ponto a jurisprudência o TJUE ramifica-se em vários possíveis sentidos. ${ }^{59}$ Num primeiro sentido, a comparabilidade das entidades concorrentes deve ser aferida em função dos objectivos da medida considerada como au-

54 TJUE, caso C-148/04, Unicredito Italiano, 15 de Dezembro de 2005, [2005] I-11137, parágrafo 45.

55 TJUE, caso C-15/14 P, MOL Magyar Olaj, 4 de Junho de 2015 (ainda não publicado).

56 TJUE, caso C-143/99, Adria-Wien Pipeline, 8 de Novembro de 2001, [2001] I-08365, parágrafo 41; TJUE, caso C-487/06 P, British Aggregates/Comissão, 22 de Dezembro de 2008, [2001] I-10515, parágrafo 82.

57 Conclusões do advogado-geral Niilo Jääkkinen apresentadas em 8 de Julho de 2010 nos processos apensos C-78-80/08, Paint Graphos e Outros, [2011] I-07611, par. 80. Sobre este particular aspecto, Mikel Azcoaga Ibarra, "Tax treatment of cooperatives and EU State aid policy», GEZKI-Revista Vasca de Economía Social, n. ${ }^{\circ} 1$ (2014), pp. 117-118.

58 MOL Magyar Olaj (C-15/14 P); Adria-Wien Pipeline (C-143/99), parágrafo 41; British Aggregates/Comissão (C-487/06 P), parágrafo 82; TJUE, casos C-106/09 P e C-107/09 P, Comissão e Espanha/Governo de Gibraltar, 15 de Novembro de 2011, [2011] I-11113, parágrafo 75.

59 Conclusões do Advogado-Geral Niilo Jääskinen nos processos apensos C-78/08 a C-80/08, Paint Graphos e Outros, par. 80. 
xílio. ${ }^{60}$ Por exemplo, se é criado um regime de apoio às empresas de produção de energia de fontes renováveis, cujo objectivo é promover a produção de energia de fontes renováveis, à vista deste objectivo, os restantes subsectores de produção energética (empresas de produção de energia de fontes não renováveis) nunca estariam numa situação comparável. ${ }^{61}$ Esse entendimento, contudo, desemboca num raciocínio tautológico, pois se a medida fiscal tem como objectivo favorecer um sector ou conjunto de entidades, o seu âmbito de aplicação será definido precisamente pelas características diferenciadoras dessas entidades, de modo que o critério da comparabilidade nunca se verificará.

Noutros casos, em sentido contrário ao anterior, o Tribunal considerou que a comparabilidade deve ser aferida em função dos objectivos da lei que é derrogada pela medida que constitui o auxílio, ie do regime de aplicação mais geral. ${ }^{62}$ Assim sendo, sempre que o auxílio em causa consista em isentar um sector ou uma ou várias empresas de uma obrigação legal, como uma obrigação fiscal, a comparabilidade deve ser aferida em função das finalidades da lei de cuja aplicação ficam isentos os beneficiários da ajuda. ${ }^{63}$ Este segundo sentido tem sido utilizado pelo TJUE de forma mais consistente que o primeiro e tem sido utilizado sobretudo na jurisprudência mais recente respeitante a medidas de natureza fiscal. ${ }^{64} \mathrm{Em}$ nossa opinião, ambos os critérios podem ser adequados, dependendo das medidas em causa. ${ }^{65}$

Aspecto particularmente importante para a questão da fiscalidade das cooperativas, é que, na aplicação do critério de comparabilidade entre os beneficiários e os não beneficiários da medida, o Tribunal de Justiça tem tomado em consideração o facto de que sobre os beneficiários da medida recaiam restrições ou encargos que os que não beneficiam da medida não têm que suportar. ${ }^{66}$ Este argumento foi invocado

60 Acórdão C-417/10, 3M Italia, 29 de Março de 2012, Col. geral [2012]-00000.

61 Acórdão do Tribunal Geral (Teceira Secção), processo T-47/15, Alemanha/Comissão, de 10 de Maio de 2015 [ainda não publicado].

62 TJUE, caso C-522/13, Navantia /Concelho de Ferrol, 9 de Outubro de 2014, ainda não publicado; TJUE, caso C-5/14, Kernkraftwerke Lippe-Sem v. Hauptzollamt Osnabrück, 4 de Junho de 2015, ainda não publicado; TJUE, caso C-88/03, Portugal/Comissão, 6 de Setembro de 2006, [2006] I-07115.

63 Marie-Ann Kronthaler, e Yinon Tzubery, «The state aid provisions of the TFEU in tax matters», em Introduction to European Tax Law on Direct Taxation, ed. por Michael Lang, Pasquale Pistone, Josef Schuch e Claus Staringer (Viena: Linde Verlag, 2015), p. 110.

64 TJUE, caso C-730/79, Philip Morris, 17 de Setembro de 1980, [1980] 2671.

65 Nina Aguiar, "Princípios cooperativos e benefícios fiscais», CIRIEC-España, Revista Jurídica de Economia Social e Cooperativa, n. ${ }^{\circ} 27,(2015)$.

66 TJUE, 14 de Janeiro de 2015, caso C-518/13, Eventech. Sobre este ponto, MERINO JARA, I., op. cit., p. 35. 
pela Comissão para justificar a compatibilidade com o regime das ajudas de custo das medidas objecto de litígio no processo Associação de Estações de Serviço de Madrid /Comissão, ${ }^{67}$ aplicável às cooperativas agrárias em Espanha.

\subsubsection{JUSTIFICAÇÃO DO TRATAMENTO EXCEPCIONAL PELA NATUREZA OU ECONOMIA DO REGIME GERAL}

Na sentença Tiercé Ladbroke/Comissão, ${ }^{68}$ o Tribunal de Justiça afirmou que uma diferenciação de tratamento não constitui uma vantagem selectiva quando tal diferença de tratamento é justificada por razões relacionadas com a lógica do sistema. Uma medida que, prima facie, consiste num tratamento diferenciado de uma empresa ou sector de actividade pode não ser considerada selectiva se puder ser justificada com base na natureza ou economia do regime geral. ${ }^{69}$ Esta justificação é particularmente importante no caso das ajudas de estado de natureza fiscal. ${ }^{70}$ Na sua comunicação de 1998 sobre a aplicação das regras sobre ajudas de estado às medidas de natureza fiscal, ${ }^{71}$ a Comissão diz sobre estas medidas que "são medidas cuja ratio económica as torna necessárias para o funcionamento e eficiência do sistema fiscal» ${ }^{72}$ e dá como exemplo a não tributação das fundações e associações em imposto sobre os lucros. A medida, aparentemente excepcional, é apenas uma consequência lógica de as fundações e as associações não terem fins lucrativos e, como tal não poderem gerar lucros, no dizer da Comissão. ${ }^{73}$

67 TJUE, Caso T-146/03, Associação de Empresários de Estações de Serviço da Comunidade Autónoma de Madrid/Comissão, 12 de Dezembro de 2006, [2006] II-00098.

68 TJUE, caso T-504/93, Tiercé Ladbroke/Comissão, 15 de Setembro de 1995, [1997] 1-07007. Vd. também o acórdão do TJUE no processo T-210/02, British Aggregates/Comissão, de 7 de Março de 2012, Col. geral.

69 Pierpaolo Rossi Maccanico, "The Point on selectivity in state aid review of business tax measures», em Legal Remedies in European Tax Law, ed. por Sebastian Pfeiffer e Marlies Ursprung-Steindl (Amesterdão: IBFD, 2009), p. 227; Claire Micheau, "State aid and taxation in European Union Law», em Research Handbook on European State Aid Law, ed. por Erika Szyszczak, (Cheltenham : Edward Elgar Publishing, 2011), p. 203.

70 Francesco de Cecco, State Aid and the European Economic Constitution (Londres: Bloomsbury Publishing, 2012), p 105.

71 Comissão Europeia, Comunicación relativa a la aplicación de las normas sobre ayudas estatales a las medidas relacionadas con la fiscalidad directa de las empresas [Diario Oficial C 384 de 10.12.1998].

72 Ibidem [23].

73 Ibidem [25] 


\subsection{Afectação do comércio intracomunitario}

Em último lugar, para que a intervenção estatal controvertida se considere uma ajuda incompatível com o mercado interno, é necessário que possa afectar os intercâmbios comerciais entre Estados membros. $^{74} \mathrm{~A}$ este respeito, resulta da jurisprudência do Tribunal de Justiça que sempre que uma ajuda estatal fortalece a posição de uma empresa frente a outras empresas que concorrem com a pri nos intercâmbios intracomunitários, tal é suficiente para considerar que esses intercâmbios são afectados pela ajuda. Para este efeito, não é necessário que a empresa beneficiária realize efectivamente actividades intracomunitárias mas apenas que exista essa possibilidade. Uma vez que, quando um Estado membro concede una ajuda a uma empresa, a produção interna desse Estado pode manter-se ou aumentar, com a consequência de que diminuem com isso as possibilidades das empresas estabelecidas noutros Estados membros de exportar os seus produtos para o mercado desse Estado membro, a ajuda tem como efeito potencial favorecer a posição das empresas beneficiárias no mercado intracomunitário..$^{75} \mathrm{O}$ que se exige é que o beneficiário da ajuda venda bens ou serviços que se comercializem no mercado comum. ${ }^{76}$

\section{Análise da jurisprudência do Tribunal de Justiça sobre a compatibilidade dos regimes fiscais das cooperativas com o regime europeu das ajudas de estado}

\subsection{Sinopse da jurisprudência do Tribunal de Justiça em matéria de fiscalidade das cooperativas}

\subsubsection{Caso Asociación de Estaciones de Servicio de Madrid e Federación Catalana de Estaciones de Servicio/Comissão}

Não existem, até ao momento, muitas decisões do TJUE em matéria de fiscalidade cooperativa. Como bem observa $A L G U A C I L,{ }^{77}$ a questão da fiscalidade das cooperativas começou a tornar-se relevante no plano do direito europeu da concorrência apenas quando a legislação

74 TJUE, caso C-310/99, Italia/Comissão, 7 de Março de 2002, [2002] 1-02289.

75 TJUE, processos acumulados C-278/92 a C-280/92, España/Comissão, 14 de Setembro de 1994, [1994] I-4103, parágrafo 40.

76 Leigh Hancher, Tom Ottervanger e Piet Jan Slot, EU State Aids (Londres: Sweet \& Maxwell, 2012), p. 59.

77 Alguacil, P., Condicionantes..., cit., p. 30. 
cooperativa se tornou mais flexível, ao ponto de se encontrarem criadas condições para que as cooperativas entrassem efectivamente em concorrência com as demais entidades empresariais, o que é um fenómeno relativamente recente. Por isso mesmo também, uma vez que o processo de flexibilização da legislação cooperativa continua em curso. $^{78}$

A pri decisão do Tribunal de Justiça sobre a matéria foi proferida no caso Associação de Estações de Serviço de Madrid /Comissão, ${ }^{79} \mathrm{em}$ que se discutiu a compatibilidade com o regime dos auxílios de estado de uma medida do Estado espanhol que ampliava o regime de bonificação fiscal dos rendimentos das cooperativas agrícolas relacionados com a venda de combustíveis. O regime fiscal das cooperativas espanhol (artigo 93 da Lei 27/1999) classifica as cooperativas em várias categorias para efeitos fiscais, sendo que uma delas é a das cooperativas «especialmente protegidas». Esta categoria é a que goza do regime fiscal mais favorável. 80 As cooperativas agrárias são consideradas cooperativas especialmente protegidas, o que lhes confere a possibilidade de gozar de uma taxa reduzida no imposto sobre sociedades, sobre todos os resultados cooperativos, incluindo os resultados obtidos nas operações com terceiros, desde que cumpram os requisitos que a lei thes impõe. ${ }^{81}$ Por outro lado, o normativo que rege as cooperativas agrárias em Espanha autoriza-as a realizar operações com terceiros até ao limite máximo de $50 \%$ do total das realizadas com sócios. A observância deste limite é condição para que as cooperativas possam gozar do estatuto de cooperativas especialmente protegidas.

Em 2000, foi aprovado um diploma ${ }^{82}$ destinado a paliar os efeitos negativos da subida do preço dos combustíveis, que isentava as cooperativas agrárias de respeitar o limite referido anteriormente para a prática de operações com terceiros, sem perder a classificação de «especialmente protegidas».

78 Veja-se o caso do novo Código Cooperativo português, sobre o qual se publicou recentemente o estudo de , D. e Ramos, M. E., Governação e regime económico das cooperativas (Porto: Vida Económica, 2014).

79 Sentença Associação de Empresários de Estações de Serviço da Comunidade Autónoma de Madrid/Comissão, supra, nota 66.

80 Sofía Arana Landín, «El régimen fiscal de las cooperativas españolas en la Unión Europea: conclusiones para las líneas de reforma del cooperativismo español», GEZKKRevista Vasca de Economía Social, n. ${ }^{\circ}$ 7, (2011), 77-98.

81 Ibidem, p. 86.

82 Real Decreto-ley 10/2000, de medidas urgentes de apoio aos sectores agrário, pesqueiro e do transporte, BOE n. ${ }^{\circ} 241$, de 7 de Outubro de 2000. 
O litígio resultou de uma queixa efectuada junto da Comissão pelos operadores do mercado de combustíveis que consideravam que esta medida prejudicava a leal concorrência e constituía uma medida de estado incompatível com os Tratados. A Comissão emitiu uma decisão em que considerava não existir ajuda de estado proibida. ${ }^{83}$ Desta decisão da Comissão foi interposto recurso pelas queixosas para o Tribunal de Justiça. ${ }^{84}$

\subsubsection{CASO COMISSÃO/GRÉCIA}

A segunda decisão do TJUE sobre fiscalidade cooperativa foi proferida em 2007, no caso Comissão /Grécia, ${ }^{85}$ em que estava em causa a isenção do imposto sobre reuniões de capitais concedida às cooperativas agrícolas e a todos os tipos de uniões ou de grupos de cooperativas.

A lei fiscal grega (artigo $17 .^{\circ}$ da Lei n. ${ }^{\circ} 1676 / 86$, de 24 de Dezembro de 1986), determinava a tributação em «imposto sobre a reunião de capitais» de certas operações como transferência de outro Estado-Membro para a Grécia da sede de direcção efectiva de uma pessoa colectiva e a transferência de outro Estado-Membro para a Grécia da sede estatutária de uma pessoa colectiva. Este imposto era aplicável às sociedades comerciais e associações profissionais e às organizações cooperativas de qualquer nível. Porém, e aqui residia o problema, a mesma lei isentava do imposto sobre reuniões de capitais as organizações cooperativas agrícolas de qualquer nível.

O governo grego notificou a Comissão dessas medidas, ao que a Comissão respondeu com um parecer fundamentado que considerava alguns aspectos do regime fiscal notificado incompatíveis com o direito europeu (em particular com a Directiva 69/335) e convidava o governo grego a alterar o regime fiscal em causa. Na sequência da reacção do governo grego, a Comissão propôs junto do Tribunal de Justiça a acção que deu origem ao processo.

\subsubsection{Caso Paint Graphos}

A terceira decisão, e aquela que é considerada como a mais importante sentença do Tribunal até ao momento sobre a questão da fiscali-

83 Decisão 2003/293/CE relativa às medidas executadas por Espanha a favor do sector agrário após o aumento dos preços dos combustíveis (DO 2003, L 111, p. 24).

84 Sobre esta decisão, José Manuel Terejizo López, op. cit..

85 Caso C-178/05, Comissão /Grécia, 7 de Junho de 2017, [2007] I-04185. 
dade das cooperativas foi proferida em 2011 no caso Paint Graphos, ${ }^{86}$ em que estava em causa a tributação de cooperativas de trabalho em imposto sobre o rendimento italiano.

A lei fiscal italiana ${ }^{87}$ dispunha que os rendimentos das cooperativas de produção e de trabalho e dos seus agrupamentos estavam isentas do imposto sobre o rendimento das pessoas colectivas e do imposto local sobre os rendimentos «se o montante das remunerações efectivamente pagas aos membros que prestam o seu trabalho de forma continuada, (...) não for inferior a $60 \%$ do montante global de todos os outros custos, exceptuando os relativos às matérias-primas e aos fornecimentos.» $\mathrm{E}$ dispunha ainda que "se o montante das remunerações for inferior a $60 \%$, mas não a $40 \%$, do montante global dos outros custos, o imposto sobre o rendimento das pessoas colectivas e o imposto local sobre os rendimentos são reduzidos em metade.» Além disso, para determinar o rendimento das sociedades cooperativas de produção e de trabalho e dos seus agrupamentos, dispunha-se que «as importâncias pagas aos membros assalariados a título de complemento da sua remuneração podem ser deduzidas até ao limite dos salários correntes majorados em $20 \%$.»

Com referência ao ano de 1993, a administração fiscal recusou à Paint Graphos, cooperativa de produção e trabalho, o direito às isenções referidas. A Paint Graphos interpôs recurso deste acto. O processo chegou à Corte Suprema di Cassazione italiana, que interpôs reenvio prejudicial para o Tribunal de Justiça dando origem ao processo aqui referido.

\subsection{A questão da interdependência entre a tributação dos retornos dos excedentes cooperativos na pessoa dos sócios e a tributação dos resultados das cooperativas}

No caso que opôs a Associação de Estações de Serviço de Madrid e a Federação Catalã de Estações de Serviço à Comissão, já referido anteriormente, a medida aprovada pelo governo de Espanha, que autorizava as cooperativas agrárias a vender directamente combustível a terceiros, sem limitação quantitativa, sem com isso perderem a redução de os desagravamentos fiscais previstas para as cooperativas agrárias,

86 Sentença Paint Graphos, C-78-80/08, nota 56.

87 Decreto do Presidente da República n. ${ }^{\circ}$ 601, de 29 de Setembro de 1973, relativo à regulamentação dos benefícios fiscais (suplemento ordinário ao GURI n. ${ }^{\circ} 268$, de 16 de Outubro de 1973, p. 3), Artigo 11. ${ }^{\circ}$ (Cooperativas de produção e de trabalho). 
foi considerada pelo Tribunal uma medida de carácter fiscal. ${ }^{88}$ Efectivamente, de maneira indirecta, a medida alargava o âmbito de aplicação dos desagravamentos fiscais, na medida em que flexibilizava os critérios para que as cooperativas agrárias pudessem acolher-se ao estatuto fiscal de cooperativas especialmente protegidas.

A Comissão considerou que os desagravamentos fiscais específicos das cooperativas agrárias não lhes conferiam uma vantagem concorrencial, para efeitos da aplicação do conceito de ajuda de estado, e isto por dois motivos: 1) porque tais desagravamentos eram compensados (negativamente) por outras obrigações fiscais e por certas obrigações «societárias» que os restantes tipos de sociedades não têm; e 2) porque tais medidas eram coerentes com a natureza e a economia do sistema fiscal aplicável às cooperativas, não tendo, por isso carácter selectivo.

Quanto ao primeiro aspecto, as obrigações fiscais a que a Comissão se refere são a sujeição dos retornos dos excedentes cooperativos a imposto sobre o rendimento das pessoas físicas, sob um regime de tributação que, de acordo com a Comissão, seria mais gravoso que o da tributação dos dividendos societários, na medida em que não prevê qualquer mecanismo de atenuação da dupla tributação. ${ }^{89}$ Portanto, para aferir se o regime fiscal das cooperativas agrárias conferia uma vantagem, a Comissão defendeu que que se devia ter em conta não apenas a tributação em imposto sobre sociedades mas a tributação total resultante da conjunção da tributação dos resultados cooperativos em imposto sobre sociedades com a tributação dos retornos cooperativos em imposto sobre o rendimento das pessoas físicas. ${ }^{90}$

É útil tomar em conta, a este propósito, os antecedentes da posição da Comissão quanto a esse ponto. Numa comunicação publicada em $1998,{ }^{91}$ sobre a aplicação das normas sobre ajudas estatais às medidas relacionadas com a fiscalidade directa das empresas, a Comissão afirmara o seguinte: «é evidente que o imposto sobre os lucros só é aplicável quando existam lucros. Assim, com base na natureza do sistema fiscal, pode justificar-se que as empresas sem finalidade lucrativa, como as fundações ou as associações, estejam nominalmente isentas de im-

\footnotetext{
88 Parágrafos 87 e 88.

89 Sobre este ponto, Maria Pilar Alguacil, Condicionantes.., cit., p. 37; José Manuel Terejizo López, op. cit., p. 60

90 Maria Pilar Alguacil, Tax treatment ..., cit., p. 1096.

91 Comissão Europeia, Comunicação sobre a aplicação das regras relativas aos auxílios estatais às medidas que respeitam à fiscalidade directa das empresas empresas [Jornal Oficial C 384 de 10.12.1998].
} 
posto, uma vez que não podem gerar lucros. Além disso, com base na natureza do sistema fiscal também se pode justificar que, no caso de certas cooperativas que distribuem aos seus membros todos os seus lucros, estes não sejam tributados como tal, desde que os membros estejam sujeitos a tributação por esses mesmos lucros. ${ }^{92}$ Nesta sua comunicação, portanto, a Comissão assume a postura de que a tributação dos resultados (a que chama indistintamente e sem preocupação de rigor «lucros») deve ser vista em interdependência com a tributação dos retornos cooperativos na pessoa dos sócios. E que os primeiros só devem poder ficar isentos de tributação se os retornos cooperativos forem tributados.

Em nossa opinião, esta construção enferma de vícios conceptuais, uma vez que parte de uma equiparação dos resultados cooperativos a lucros societários e dos retornos dos excedentes cooperativos a dividendos. Com efeito, em primeiro lugar, as cooperativas não podem distribuir «lucros.» As cooperativas apenas podem fazer retornar aos cooperadores os excedentes gerados nas operações cooperativizadas realizadas com os próprios cooperadores..$^{93}$ Isto significa que o retorno de excedente, na ótica do cooperador, pode ter diversas naturezas. Umas vezes, esse excedente será uma devolução de um preço pagão em excesso à cooperativa. E portanto, deverá ser contabilizado como uma redução dos custos operacionais do cooperador (imaginese o caso de um cooperador de uma cooperativa agrícola que recebe retorno de excedentes pelos serviços que a cooperativa lhe prestou). Outras vezes, o retorno de excedentes será um pagamento de um preço que a cooperativa pagou a menos (considere-se o caso de um cooperador de uma cooperativa leiteira que recebe um retorno relativo ao leite entregue à cooperativa). Neste caso, o retorno terá a natureza de um proveito, ou rendimento operacional e será tratado como tal. No caso das cooperativas de trabalho os retornos de excedente terão a natureza de rendimentos de trabalho e deverão ser tratados como tal. E finalmente, nas cooperativas de consumo e de habitação os retornos de excedentes têm a natureza de poupanças e não deverão ser tributados. Os retornos de excedentes, portanto, nunca têm natureza similar à dos dividendos, pela simples razão de que não são remuneração de

92 Ponto 25 da Comunicação, supra, nota 89.

93 Deolinda Aparício Meira: «Revisitando o problema da distinção entre excedente cooperativo e lucro societário», em Actas do II Congresso Direito das Sociedades em Revista, (Coimbra: Almedina, 2012), pp. 353-374; "O regime jurídico do excedente cooperativo. Anotação ao acórdão do supremo tribunal de justiça, de 17 de Outubro de 2002», RIDB, (2013), n. ${ }^{\circ}$ 3, pp. 2103-2123. 
capital. E, nessa medida, não cabe comparar o tratamento fiscal dado aos dois tipos de recebimentos. Não faz portanto qualquer sentido e é dogmaticamente errado sustentar, como faz a Comissão, que os resultados das cooperativas só devem ficar isentos se os retornos forem tributados.

Parece-nos ainda relevante, antes de analisar a posição do Tribunal de Justiça, referir a posição defendida pelas impugnantes sobre este ponto, para vermos também como foi a mesma considerada pelo Tribunal. As impugnantes alegaram que a posição da Comissão estava errada, pois não tinha em conta que «existe um mecanismo alternativo de retribuição aos sócios, o qual consiste no incremento do preço a que a cooperativa lhes compra os seus produtos, o que permite aos sócios receber uma quantia superior ao retorno cooperativo.» Em nossa opinião, esta posição também não é teoricamente sustentável, pois o retorno do excedente cooperativo e o preço pago pela cooperativa - no caso de uma cooperativa agrícola - aos produtores têm rigorosamente a mesma natureza, sendo diferentes apenas quanto ao momento em que ocorrem e, num plano meramente formal e não substancial, quanto ao mecanismo através do qual são estabelecidos. ${ }^{94}$

As impugnantes contestam o modo como a Comissão faz a aplicação da sua teoria ao caso concreto, por não ter em conta, quando compara a tributação do rendimento das cooperativas com a tributação das sociedades, a redução de $50 \%$ da colecta estabelecida a favor das cooperativas, a liberdade de amortização dos elementos do activo fixo, a isenção de imposto sobre transmissões patrimoniais e actos jurídicos documentados e a bonificação de $95 \%$ das colectas e adicionais nos impostos de actividades económicas e sobre bens imóveis. O erro conceptual da Comissão na abordagem ao problema, que apontámos anteriormente, é o que dá origem a esta objeção. De facto, se se opta por comparar enquadramento fiscal das cooperativas com o das sociedades, incluindo o tratamento dados aos retornos dos excedentes, saindo da esfera do imposto sobre o rendimento da cooperativa, então não há razão para limitar essa comparação ao imposto sobre sociedades. Em nossa opinião, apenas há que comparar, pelas razões que já expusemos, o imposto eu incide sobre o lucro das sociedades e o imposto que incide sobre o rendimentos das cooperativas, na esfera da cooperativa. Essa comparação poderá eventualmente estender-se à tributação dos dividendos versus a tributação dos pagamentos efetua-

94 Sobre o conceito de excedente, Deolinda Aparício: «Revisitando..., cit.; «O regime... cit. 
dos a título de remuneração de capital nas cooperativas, quando sejam permitidos pelo direito cooperativo.

O Tribunal considera que a Comissão não fundamenta suficientemente a existência de uma relação de interdependência entre a tributação dos retornos cooperativos e o regime fiscal das cooperativas. Ora, a Comissão diz claramente (considerando 147), que «a fiscalidade das cooperativas agrárias deve ser analisada no seu conjunto e responde a elementos diferenciadores quanto à sua estrutura, contendo elementos beneficiosos compensados com obrigações específicas (dotações para reservas obrigatórias, tratamento do capital, dupla tributação). E por conseguinte (considerando 148) «as modificações introduzidas na legislação das cooperativas agrárias não Ihes conferem uma vantagem que diminua os encargos que as oneram e não constituem uma medida fiscal selectiva que afecte os recursos do Estado.» Atentando nesta argumentação, percebe-se que a Comissão não considera necessário demonstrar a existência de uma relação específica entre cada desagravamento fiscal e cada desvantagem do regime fiscal cooperativo. Pelo contrário, a Comissão considera que o regime fiscal das cooperativas no seu conjunto responde aos elementos diferenciadores presentes na estrutura das cooperativas.

O tribunal rejeita esta abordagem, exigindo que se demonstre uma relação específica entre cada elemento beneficioso do regime fiscal das cooperativas e o regime de tributação dos retornos cooperativos. Ora, considerando a dificuldade evidente de levar a cabo uma tal tarefa, embora a posição do Tribunal possa não parecer totalmente conclusiva, parece-nos que a mesma praticamente invalida o argumento da interdependência entre o regime de tributação dos retornos cooperativos e o regime de tributação das cooperativas no seu conjunto.

\subsection{A questão da interdependência entre o regime fiscal favorável das cooperativas e as restrições impostas pelo regime cooperativo}

Na argumentação usada pela Comissão, a questão da relação entre o regime fiscal favorável das cooperativas e as restrições impostas pelo regime cooperativo é tratada em conjunto com a questão anterior. Também a resposta do Tribunal é a mesma para as duas questões.

Quando o propósito é teórico, porém, como neste caso, as duas questões devem ser vistas separadamente. O próprio Tribunal, como já vimos, deixa isso claro, ao recusar a abordagem da Comissão, baseada na consideração do regime fiscal das cooperativas no seu conjunto em contraposição com o conjunto das desvantagens, de carácter fiscal e não fiscal, que 
o regime das cooperativas acarreta para estas. A questão reside em saber se as características estruturais do regime substantivo das cooperativas acarretam desvantagens, qual a natureza dessas desvantagens e se essas desvantagens justificam um tratamento fiscal diferenciado.

Segundo a Comissão, as desvantagens que decorrem para as cooperativas - no caso, cooperativas agrárias- do seu regime substantivo («da sua estrutura») e que são compensadas pelo seu regime fiscal são: as dotações obrigatórias para reservas (a Comissão refere em particular a reserva legal e a reserva para educação e promoção) e o carácter irrepartível dessas reservas; e a variabilidade do capital social, em função da adesão ou saída de sócios. ${ }^{95}$

A Comissão apresenta estas desvantagens em particular como justificativas de um tratamento fiscal mais favorável das cooperativas. De referir a este propósito que a Comissão considera que os aspectos fiscais discutidos constituem benefícios fiscais. ${ }^{96}$ Portanto, para a Comissão, o facto de as cooperativas estarem obrigadas a constituir reservas legais, juntamente com o carácter irrepartível dessas reservas, e a variabilidade do capital social dessas mesmas entidades poderia ser usado como justificação para o conjunto de benefícios fiscais incluídos no regime fiscal das cooperativas.

A posição do Tribunal nesta matéria é comum com a do ponto anterior. O Tribunal considera que a argumentação da Comissão não é suficientemente fundamentada. O que, vista a argumentação da Comissão, leva a concluir que para o Tribunal as desvantagens estruturais das cooperativas não podem ser invocadas genericamente como justificação para um conjunto de benefícios fiscais de que aquelas gozam. Apenas o desenvolvimento futuro da jurisprudência do Tribunal poderá confirmar esta conclusão.

Algo nos parece certo, porém. A demonstração da compatibilidade de um regime fiscal favorável das cooperativas com o regime de judas de estado exigirá que se demonstre, em primeiro lugar, que as características estruturais das cooperativas se traduzem efetivamente em desvantagens. Por exemplo, a obrigatoriedade de constituição de reservas não é uma desvantagem comparativa das cooperativas, uma vez que as sociedades comerciais também estão obrigadas por lei a constituir reservas. Quanto à impossibilidade de repartição dessas reservas será necessário demonstrar que a mesma se traduz numa desvantagem comparativa. Em nossa opinião, como já defendemos noutro lugar, a

95 Estas duas desvantagens encontram-se indicadas de modo sumário nos considerandos 92 e 147 da Decisão da Comissão impugnada.

96 Ponto 146 da Decisão impugnada. 
impossibilidade de repartição de reservas, tal como a impossibilidade de distribuição de lucros em geral, é um fator que dificulta a formação de capital nas cooperativas. Em segundo lugar, será ainda necessário demonstrar um nexo entre a vantagem fiscal concedida e a desvantagem comparativa resultante do regime cooperativo.

\subsection{O argumento da justificação pela natureza e lógica do sistema}

No caso Associação de Estações de Serviço de Madrid/Comissão, a Comissão utilizou também, a título subsidiário, o argumento da justificação das medidas alegadamente vantajosas pela natureza e lógica do sistema. ${ }^{97}$ Segundo a Comissão, as vantagens fiscais de que as cooperativas agrárias alegadamente beneficiavam não resultariam de medidas selectivas — faltaria, portanto, o requisito da selectividadeporque o regime fiscal das cooperativas estaria plenamente justificado pela natureza e pela economia do sistema fiscal.

A Comissão desenvolve a seguinte argumentação: a natureza e a economia do sistema fiscal no âmbito das ajudas de Estado referem-se à adequação das normas fiscais aos princípios que informam o ordenamento jurídico de que se trata. Entre estes princípios figuram os da igualdade e progressividade, consagrados no artigo 31 da Constituição espanhola, nos termos do qual, «todos contribuirão para o financiamento das despesas públicas de acordo com a sua capacidade económica mediante um sistema tributário justo inspirado nos princípios de igualdade e progressividade e que em caso algum poderá terá efeito confiscatório.» A ideia central desta norma da Constituição espanhola reside no conceito de justiça distributiva, segundo o qual é tão injusto tratar de modo desigual situações que são iguais como tratar de modo igual situações que são distintas. Da própria definição de sociedade cooperativa dada pela legislação espanhola (artigo 1 da Ley 27/1999) decorre que esta sociedade reúne alguns traços característicos que a distinguem das sociedades de capital. Em primeiro lugar, a cooperativa é uma sociedade de pessoas e não de capital, o que se traduz em várias diferenças de funcionamento. Assim, a particular relação pessoal existente entre a cooperativa e os seus sócios implica que a retribuição que o socio recebe de uma cooperativa não é assimilável a uma pura retribuição de capital. Em segundo lugar, todos os sócios têm idênticos direitos na tomada de decisões da sociedade, enquanto nas sociedades

97 Sobre esta questão, Maria Pilar Alguacil, Condicionantes..., cit., pp. 42-46. 
de capital tais direitos estão essencialmente em função da participação no capital social. Por outro lado, o capital social de uma cooperativa é variável, em função da adesão e saída dos sócios e a sua importância é menor que numa sociedade de capital, do que decorre a maior importância das reservas obrigatórias, a que se destinam prioritariamente os lucros. Além disso, os sócios de uma cooperativa devem participar na actividade empresarial desenvolvida pela cooperativa. Por outro lado, os lucros que sejam distribuídos aos sócios de uma cooperativa não são comparáveis, nem quanto ao seu volume nem quanto à sua natureza, com os lucros distribuídos por uma sociedade de capital aos seus accionistas. Por último, a retribuição que o socio recebe numa cooperativa não é assimilável sem mais a uma pura retribuição de capital. ${ }^{98} \mathrm{Em}$ suma, o argumento da Comissão pode resumir-se do seguinte modo: se o princípio da igualdade tributária exige que se trate de maneira diferente o que é diferente, as cooperativas devem receber um tratamento fiscal diferente das sociedades de capital em virtude das suas características específicas.

Deste modo, o argumento da Comissão entrelaça a questão da selectividade das medidas fiscais com a questão da igualdade tributária. Como já sustentámos noutro local, ${ }^{99}$ a questão da selectividade das medidas fiscais beneficiosas cruza-se, efectivamente, com o princípio da igualdade tributária. A concessão de benefícios fiscais, não estando justificada por um fim de interesse público e com dignidade constitucional, se no plano da concorrência pode ofender o regime das ajudas de estado, no plano do direito fiscal será uma medida contrária ao princípio da igualdade tributária.

Infelizmente, a Comissão oferece sobre este ponto uma argumentação incompleta e incongruente, pois, como é bem patente, não é suficiente argumentar que as cooperativas têm especificidades de regime para justificar diferenciações no regime fiscal, mas é necessário demonstrar que existe uma relação entre essas especificidades e o tratamento fiscal concedido. ${ }^{100}$ Parece ser esta também a posição do Tribunal de Justiça, que afirma que a argumentação da Comissão neste ponto é incompreensível. ${ }^{101}$

98 Sentença Associação de Estações de Serviço de Madrid/Comissão, parágrafo 106.

99 Nina Aguiar, Princípios..., cit., p. 255.

100 Maria Pilar Alguacil, Condicionantes..., cit., p. 44, observa a propósito que «a justificação com base na natureza ou na economia do sistema não significa que qualquer diferença objectiva legitime um tratamento beneficioso mas que os critérios de selecção dos beneficiários devem ser inerentes à lógica do sistema fiscal em causa».

101 Sentença Associação de Estações de Serviço de Madrid/Comissão, parágrafos 116 a 121. 
Temos dúvidas de que a função social das cooperativas ou o interesse público da sua promoção como justificativos da diferenciação do regime fiscal possam ser invocados ao abrigo do argumento da justificação pela natureza e lógica do sistema, ${ }^{102}$ uma vez que não encontramos na natureza e lógica do sistema fiscal quaisquer elementos que possam justificar as diferenciações de regime fiscal de que gozam as cooperativas nos casos analisados. Por outro lado, parece-nos que procurar ver nos fins de natureza extrafiscal, sejam eles a promoção da economia cooperativa, a protecção ambiental ou quaisquer outros, a natureza e a lógica do sistema, conduziria a que quaisquer benefícios fiscais estariam sempre justificados pela natureza e a lógica do sistema, desde que visassem um fim extrafiscal comprovadamente de interesse público, o que não nos parece ser o espírito do argumento da natureza e lógica do sistema. ${ }^{103}$ Parece-nos ter razão FRESCURATO ${ }^{104}$ ao sustentar que, em matéria fiscal, dois tipos de justificações baseadas na natureza e na economia do sistema fiscal têm um papel principal. O primeiro é o princípio da neutralidade, que visa eliminar distorções do sistema fiscal, enquanto o segundo respeita à necessidade de evitar a evasão fiscal.

\subsection{A natureza não lucrativa das cooperativas como justificativa de um regime fiscal diferenciado}

O caso C-178/05 Comissão/Grécia diz respeito à transposição efectuada pela Grécia da Directiva 69/335, ${ }^{105}$ que previa a aplicação de um imposto sobre as entradas de capital. O artigo 1 da Directiva 69/335 previa que os Estados-Membros cobrariam um imposto sobre as entradas de capital em "sociedades de capitais». No entanto, o artigo 3.2 da Directiva equiparava às sociedades de capitais toda e qualquer outra sociedade, associação ou pessoa colectiva «com fins lucrativos». A legislação grega que transpôs a Directiva isentava desse imposto, entre outras entidades, as cooperativas agrícolas, por considerar que as

102 Como parece defender Maria Pilar Alguacil, Condicionantes..., cit., p. 46.

103 Cfr. Os acórdãos do TJUE nos processos C-143/99, Adria-Wien Pipeline, de 8 de Novembro de 2001, Col. de Jur. 2001 I-08365; e C-C-173/73, Itália/Comissão, de 2 de Julho de 1974, Col. de Jur. 197400709.

104 Daniele Frescurato, "State aid issues in VAT and direct taxation», em Global Trends in VAT/GST and Direct Taxation, ed. por Sebastian Pfeiffer, Marlies UrsprungSteindl (Viena: Linde, 2015), p. 695.

105 Directiva 69/335/CEE do Conselho, de 17 de Julho de 1969, relativa aos impostos indirectos que incidem sobre as reuniões de capitais. JO L 249, 3.10.1969, p. 25-29. 
cooperativas agrícolas previstas na legislação grega não podiam ser consideradas sociedades de capitais para efeitos de aplicação da Directiva.

A questão decisiva para o desfecho do pleito foi a consideração das cooperativas como entidades que podem ter fins lucrativos. A Comissão defendeu, a este propósito, que o critério do fim lucrativo deve ser compreendido de uma forma ampla, de modo a abranger não apenas as situações em que uma entidade tem como objectivo a obtenção de rendimento de um capital mas as situações, como é o caso de uma cooperativa agrícola, em que o resultado económico da sua actividade leva à atribuição de vantagens directas aos seus sócios e ao reforço económico da sociedade enquanto comunidade solidária, ainda que isto não resulte no pagamento directo de um rendimento do capital. ${ }^{106}$

O Tribunal de Justiça, por seu turno, acatando a posição da Advogada-Geral, afirmou que "as cooperativas agrícolas em questão prosseguem uma actividade económica que, sem especificamente ter por objectivo obter lucros financeiros, é, contudo, reputada aumentar o desenvolvimento económico e social dos seus membros.» E por essa razão "prosseguem um fim lucrativo». ${ }^{107}$

Obviamente, esta posição do Tribunal tem que ser entendida no seu contexto. O Tribunal de Justiça não enuncia uma proposição definitiva sobre a natureza das cooperativas agrícolas como entidades lucrativas ou não lucrativas. Mas para efeitos de regime fiscal, o Tribunal considera que o facto de as cooperativas não visarem a reprodução do capital financeiro não justifica, por si, uma diferenciação.

A mesma conclusão é reforçada pela jurisprudência emanada do caso Cassa di Risparmio di Firenze, ${ }^{108}$ em que o Tribunal de Justiça considerou que uma fundação que resultara da cisão das actividades de um banco levava a cabo actividades económicas que não podiam ser qualificadas como tendo uma natureza exclusivamente social, devendo por isso a fundação ser qualificada como empresa para efeitos do artigo 107(1) do TFEU. ${ }^{109}$ Daqui é possível inferir, acompanhando CUSA, ${ }^{110}$ que o fim lucrativo ou não lucrativo de uma entidade não

106 Esta concepção sobre o fim lucrativo foi acolhida pela Advogada-Geral Juliane Kokott (Opinião no processo C-178/05, parágrafo 60).

107 Caso C-178/05 Comissão /Grécia parágrafo 42. Aparentemente no mesmo sentido, ALGUACIL, P., Condicionantes...,. cit., p. 30.

108 TJUE, caso C-222/04, Cassa di Risparmio di Firenze, de 10 de Janeiro de 2006, Col de Jur. [2006] I-00289.

109 Ibidem, parágrafo 125.

110 CUSA, E., op. cit, p. 1108. 
constitui factor decisivo para distinguir uma empresa de outra para efeitos da aplicação do regime europeu dos auxílios de estado.

Parece-nos antes de mais, em relação a este ponto, que falta precisão no uso do termo "fins lucrativos», quando se refere o mesmo às cooperativas ou ao setor da economia social em geral. A conceção segundo a qual tem fins lucrativos a entidades que tem como fim produzir vantagens económicas diretamente na esfera patrimonial dos membros é uma tese com créditos firmados na doutrina. ${ }^{111}$ Nessa medida, as cooperativas, ou algumas cooperativas, seriam sempre entidades com fins lucrativos. ${ }^{112}$ Mas além do mais, as cooperativas gozam de uma ampla margem para desenvolverem atividade com não membros, que levam à acumulação de capital. Se este lucro objetivo se pode transformar em lucro subjetivo (distribuição aos membros), é uma questão complexa. Em nossa opinião, o lucro objetivo transformase em lucro subjetivo sempre que a cooperativa pratica, nas operações que realiza com os sócios, preços mais favoráveis que os de mercado. Sendo assim, o argumento do fim não lucrativo das cooperativas não parece oferecer uma base sólida para sustentar a defesa de um regime fiscal mais favorável para estas entidades.

\subsection{A questão do quadro de referência}

Como já anteriormente se referiu, a qualificação de uma medida fiscal nacional como selectiva exige, em primeiro lugar, que se estabeleça o quadro de referência, ie o regime à luz do qual se analisa se existe um tratamento diferenciado, já que uma medida será selectiva apenas se for vantajosa em relação às condições que são aplicadas aos restantes operadores económicos. ${ }^{113}$ A questão do quadro de referência a utilizar no caso da fiscalidade cooperativa foi também abordada pela Comissão no caso Associação de Estações de Serviço de Madrid/Comissão. A Comissão defendeu aí que o regime fiscal das

111 Em Portugal, vg. Luís Cabral de Moncada, Lições de Direito Civil, 4. ${ }^{a}$ ed. (Coimbra: Almedina, 1995), p. 121.

112 Neste sentido María Pilar Alguacil, Concidionantes..., cit., p. 30; Manuel Paniagua Zurera, "La determinación y la distribución de los resultados del ejercicio económico en la Sociedad cooperativa: propuestas de armonización legislativa», em Revista de derecho de sociedades, (2005), n.24, p. 202.

113 TJUE, acórdãos nos processos apensos C-106/09P e C-107/09P, Comissão/Governo de Gibraltar, de 15 de Novembro de 2011, Col. de Jur. 2011 l-11113; e acórdão no processo C-88/03, Portugal/Comissão, de 6 de Setembro de 2006, Col. de Jur. I-7115. 
cooperativas — no caso agrárias - não devia ser comparado com o regime fiscal das sociedades, o que equivale a dizer que o regime fiscal das sociedades não deveria ser tomado como quadro de referência, uma vez que as especificidades das cooperativas justificam um regime fiscal diferenciado. Por conseguinte, o regime fiscal das cooperativas seria um regime autónomo, com a sua própria lógica e que não implica uma diferenciação em relação a nenhum regime geral. $O$ argumento da Comissão não chegou a ser apreciado pelo Tribunal, o que pensamos poder ser justificado pela inconsistência da sua formulação. Com efeito, a Comissão admitiu, na sua Decisão, estar perante benefícios fiscais concedidos às cooperativas, o que é, em si, já uma negação de que o regime fiscal cooperativo em causa fosse um regime autónomo, já que os benefícios fiscais são excepções a um regime fiscal geral.

No caso Paint Graphos, a questão foi de novo suscitada, tendo o Tribunal concluído que o quadro de referência, no caso, era constituído pelo imposto sobre o rendimento das sociedades. ${ }^{114}$ Para justificar esta posição, o Tribunal limita-se a observar que, "para efeitos da determinação do imposto sobre o rendimento das sociedades, a base tributável das sociedades cooperativas de produção e de trabalho em causa é determinada do mesmo modo que a dos restantes tipos de sociedades, isto é, em função do montante do lucro líquido resultante do exercício da actividade da empresa no termo do ano fiscal.» Assim, prossegue o Tribunal, «há que considerar que o imposto sobre as sociedades constitui o regime jurídico de referência para apreciar o eventual carácter selectivo da medida em causa.

A questão — se o regime fiscal das cooperativas deve ou não ser comparado, para efeitos de aplicação do regime das ajudas de custo com o regime fiscal das sociedades- é de fundamental importância nesta matéria e a jurisprudência do Tribunal de Justiça no caso Paint Graphos de maneira nenhuma a encerra. O que a jurisprudência do Tribunal de Justiça no caso Paint Graphos nos diz sobre ela é que se, num dado ordenamento, o regime fiscal das sociedades é aplicável, genericamente, às cooperativas, e se sobre esse regime genérico se estabelece um conjunto de normas de carácter especial para as cooperativas, o regime fiscal das sociedades será tomado como regime de referência. Em nossa opinião, o ser ou não, o regime fiscal das sociedades genericamente aplicável às cooperativas é um aspeto meramente formal, sistemático, de organização legislativa, que não é relevante para a determinação do quadro de referência. Há que atender, sim, ao quadro da

114 Sentença C-78/08 a C-80/08, Paint Graphos e Outros, parágrafos 49 a 50. 
tributação da manifestação de riqueza em causa. Se se estiver a considerar a tributação do rendimento, há que tomar como quadro de referência a tributação do rendimento para todos os tipos de sujeitos passivos. O quadro de referência será dado pelos princípios e regras fundamentais da tributação do rendimento num determinado orenamento.

\subsection{A questão da comparabilidade entre as cooperativas e as sociedades comerciais}

Na sentença Paint Graphos, para analisar a questão da existência de um tratamento fiscal das cooperativas no direito italiano, relativamente às cooperativas de produção e trabalho, o Tribunal partiu da premissa de que as isenções de imposto sobre o rendimento previstas pela lei para estas cooperativas constituíam benefícios fiscais. Em nossa opinião, esta premissa é discutível. As cooperativas têm diversos tipos de resultados, sendo que, em relação a alguns desses resultados, nomeadamente os resultados provenientes de operações cooperativizadas com sócios, quando sejam pagos retornos aos cooperadores no mesmo ano, pelo menos, não será correcto falar em rendimento da cooperativa.

Partindo do princípio de que a isenção de imposto sobre o rendimento que a lei italiana estabelecia a favor das cooperativas de produção e trabalho era um benefício fiscal, o Tribunal centrou a discussão sobre a selectividade da medida na questão da comparabilidade (entre as cooperativas e as sociedades comerciais). ${ }^{115}$

Para tal, o Tribunal toma em conta as características que são específicas das cooperativas e as distinguem dos «restantes operadores económicos», descrevendo essas características com base no Regulamento 1435/2003. Essas características são o princípio da primazia da pessoa, «que se manifesta através de disposições específicas relativas às condições de admissão, demissão e exclusão dos membros»; A impossibilidade de repartição dos activos líquidos e das reservas em caso de dissolução da cooperativa; no plano da gestão, o facto de as cooperativas não serem geridas com vista a favorecer investidores externos, mas para satisfazer os interesses comuns dos sócios, e o facto de o controlo da cooperativa ser equitativamente repartido pelos seus membros, reflectindo a regra «uma pessoa, um voto»; no plano do

115 Sentença C-78/08 a C-80/08, Paint Graphos e Outros, parágrafo 56. 
funcionamento, o facto de as cooperativas terem como finalidade o proveito mútuo dos seus membros, que são ao mesmo tempo utilizadores, clientes ou fornecedores, de modo que cada um recebe o lucro das actividades da cooperativa em função da sua participação nesta e das suas transacções com a cooperativa; O facto de as cooperativas terem um acesso limitado ao mercado de capitais, de modo que o seu desenvolvimento depende de fundos próprios ou do crédito, o que resulta de as participações das sociedades cooperativas não serem negociáveis e de a remuneração do capital mutuado e das participações ser limitada, tornando o investimento numa sociedade cooperativa menos proveitoso. ${ }^{116}$

Para além destas características, que o Tribunal enumera com base no Regulamento 1435/2003, portanto partindo de elementos normativos, o Tribunal conclui ainda, sem explicações, que «a margem de lucro deste tipo específico de sociedades (cooperativas) é claramente inferior à das sociedades de capitais, que se podem melhor adaptar às exigências do mercado.» ${ }^{117}$

Da enumeração das «características particulares próprias das sociedades cooperativas», o Tribunal extrai a conclusão de que, «em princípio, não se pode considerar que sociedades cooperativas de produção e de trabalho como as que estão em causa no processo principal estejam numa situação de facto e de direito comparável à das sociedades comerciais, desde que, todavia, prossigam o interesse económico dos seus membros e mantenham uma relação não meramente comercial, mas pessoal particular com estes últimos, na qual os seus membros estão activamente implicados e têm direito a uma repartição equitativa dos resultados económicos.»118

Esta conclusão final do Tribunal é ambígua. Após ter enumerado, com base em elementos normativos objectivos, as características das cooperativas, o Tribunal poderia ter concluído simplesmente que as cooperativas que obedecessem a essas características legalmente definidas não estão numa situação de facto e jurídica comparável à das sociedades comerciais. No entanto, o Tribunal acrescenta uma condição: «desde que prossigam o interesse económico dos seus membros e mantenham uma relação não meramente comercial, mas pessoal par-

116 Emmanuele Cusa, op. cit., p. 1115.

117 Ibiem, parágrafo 60.

118 Emmanuele Cusa, op. cit., p. 1115, analisando a sentença no caso Paint Graphos, observa que o Tribunal considera como não estando numa situação de comparabilidade jurídica e de facto com as sociedades comerciais apenas as «verdadeiras cooperativas». 
ticular com estes últimos, na qual os seus membros estão activamente implicados e têm direito a uma repartição equitativa dos resultados económicos.»Em termos objectivos, o que se retira desta condição é que, para não se considerar uma cooperativa numa situação comparável à das sociedades comerciais, é necessário que os sócios participem efectivamente na actividade da cooperativa e recebam retornos cooperativos.

Mais uma vez, é necessário ter em conta que a abordagem do Tribunal de Justiça é marcadamente casuística e nem sempre é viável extrair dela regras com validade geral. A dificuldade de extrair uma regra geral da decisão aqui exposta resulta de o Tribunal nada dizer quando à medida em que será de exigir a efectiva participação dos sócios na actividade da cooperativa e o pagamento de retornos. Por outras palavras, sabendo-se que as cooperativas podem, de acordo com os princípios cooperativos definidos pela Aliança Cooperativa Internacional, desenvolver operações cooperativizadas com terceiros, e que as cooperativas não estão obrigadas, e na maior parte dos casos está-lhes mesmo vedada a distribuição a totalidade os excedentes cooperativos, a decisão do Tribunal não dá qualquer indicação quanto à proporção que é preciso observar-se numa cooperativa entre operações com sócios e operações com terceiros nem quanto à medida em que a cooperativa deve efectuar retornos de excedentes. Resulta, porém, claramente da sentença Paint Graphos que uma cooperativa pode ser considerada numa situação não comparável com uma sociedade comercial mesmo quando desenvolva operações com terceiros. ${ }^{119}$

\section{Conclusão}

Não oferece qualquer dúvida que a questão da fiscalidade das cooperativas tem que passar pelo crivo do regime das ajudas de estado do direito da União Europeia, regime esse contido actualmente no artigo 107(1) do TFEU. ${ }^{120}$ Com efeito, está perfeitamente assente que as cooperativas são empresas no pleno sentido do termo para efeitos das regras de concorrência.

Das inúmeras questões que se suscitam no âmbito da problemática da fiscalidade das cooperativas, é preciso referir que poucas são as que foram até agora discutidas na jurisprudência do Tribunal de Justiça.

119 Emmanuele Cusa, op. cit., p. 1116.

120 Juan José Hinojosa Torralvo, op. cit., p. 87. 
Assim, o alcance do contributo da jurisprudência do Tribunal de Justiça para a dilucidação da questão de saber até que ponto as cooperativas podem ou devem ter um tratamento fiscal favorável ainda é necessariamente limitado.

Uma questão que não se encontra esclarecida e que foi suscitada nos casos analisados é a da determinação do quadro jurídico (fiscal) de referência. A questão está por sua vez relacionada com uma outra de alcance mais amplo, que é a da comparabilidade entre as cooperativas e as sociedades comerciais. No entanto, a título prévio à questão da comparabilidade, é possível concluir que, na medida em que o regime fiscal das cooperativas se encontre desenhado como um conjunto de excepções aos regimes fiscais aplicáveis às sociedades comerciais, como é regra nos ordenamentos fiscais de que temos conhecimento, como o português, o espanhol e o italiano, formalmente o regime fiscal cooperativo será um regime excepcional e, por conseguinte, o regime fiscal das sociedades comerciais não poderá deixar de ser tomado como o quadro de referência, como ficou patente quer no caso Associação de Estações de Serviço de Madrid quer no caso Paint Graphos. Nada impediria, em termos formais, que o legislador estabelecesse para as cooperativas um regime de tributação próprio e autónomo, como acontece, no ordenamento português, com as entidades sem fins lucrativos. Em termos substanciais, porém, a possibilidade de um regime fiscal cooperativo autónomo está dependente da solução da questão da comparabilidade entre as cooperativas e as sociedades comerciais.

A questão da comparabilidade entre as cooperativas e as sociedades comerciais é a questão fulcral da problemática da compatibilidade de um regime fiscal cooperativo, autónomo ou excepcional, com o regime das ajudas de estado do direito da união europeia. A questão tem sido discutida com base num conjunto de características específicas das cooperativas. No caso Paint Graphos, o Tribunal considerou como características estruturais das cooperativas: o princípio da primazia da pessoa, "que se manifesta através de disposições específicas relativas às condições de admissão, demissão e exclusão dos membros»; a impossibilidade de repartição dos activos líquidos e das reservas em caso de dissolução da cooperativa; o facto de as cooperativas não serem geridas com vista a favorecer investidores externos, mas para satisfazer os interesses comuns dos sócios, e o facto de o controlo da cooperativa ser equitativamente repartido pelos seus membros, reflectindo a regra "uma pessoa, um voto»; o facto de as cooperativas terem como finalidade o proveito mútuo dos seus membros, que são ao mesmo tempo utilizadores, clientes ou fornecedores, de modo que cada um recebe o lucro das actividades da cooperativa em função da sua par- 
ticipação nesta e das suas transacções com a cooperativa; o facto de as cooperativas terem um acesso limitado ao mercado de capitais, de modo que o seu desenvolvimento depende de fundos próprios ou do crédito, o que resulta de as participações das sociedades cooperativas não serem negociáveis e de a remuneração do capital mutuado e das participações ser limitada, tornando o investimento numa sociedade cooperativa menos proveitoso.

Porém, até hoje, nem o Tribunal nem a Comissão se pronunciaram no sentido de que uma cooperativa que obedeça estritamente às características legais próprias do seu regime, nomeadamente as estabelecidas no Regulamento 1435/2003, fica, por esse facto, automaticamente numa situação de incomparabilidade com as sociedades comerciais. No acórdão Paint Graphos, o Tribunal terminou dizendo que «incumbirá ao órgão jurisdicional de reenvio apreciar (...) se as sociedades cooperativas em causa no processo principal se encontram, de facto, numa situação comparável à de outros operadores que assumem a forma de entidades jurídicas com fins lucrativos (...)». ${ }^{121}$ Por sua vez, a Comissão, no projecto de comunicação sobre auxílios de estado, diz: "tendo em conta estas especificidades, pode considerar-se que as cooperativas não se encontram numa situação factual e jurídica comparável à das sociedades comerciais, de modo que um tratamento fiscal privilegiado das cooperativas pode não ser abrangido pelo âmbito de aplicação das regras em matéria de auxílios estatais, desde que: atuem de acordo com os interesses económicos dos seus membros; as suas relações com os membros não sejam puramente comerciais, mas pessoais e individuais; os membros participem ativamente na gestão da empresa; e tenham direito à distribuição equitativa dos resultados do desempenho económico. No entanto, caso se conclua que a sociedade cooperativa objeto de análise é comparável às empresas comerciais, é necessária uma segunda fase para determinar se o regime fiscal em causa for justificado pela lógica do sistema fiscal».122

As reservas maiores das duas instituições prendem-se com a realização, por parte das cooperativas, de operações com terceiros ${ }^{123}$ que, no entanto, estão previstas no artigo 1(4) do Regulamento e na maior parte das legislações europeias, em consonância, aliás, com os princípios cooperativos definidos pela Aliança Cooperativa Internacional. ${ }^{124}$

121 Parágrafo 82. Sobre este aspecto, Emmanuele Cusa, op. cit., p. 116.

122 Comissão Europeia, Projecto..., cit., nota 3.

123 Sobre este ponto, Maria Pilar Alguacil, Condicionantes..., cit., pp. 40-42, com particular referência às decisões da Comissão Europeia sobre a questão.

124 Emmanuele Cusa, op. cit., p. 113. 
Haveria, portanto, que estabelecer um nexo entre cada uma ou várias das características estruturais e o particular regime fiscal diferenciado que se pretende aplicar às cooperativas ou, pelo menos, procurar explicar como as diversas características estruturais das cooperativas se articulam com o seu tratamento fiscal. Aspecto fundamental, a nosso ver, nesta matéria, é a da consideração dos excedentes cooperativos como rendimentos economicamente equiparáveis a lucros ou como algo substancialmente distinto que, por esse mesmo facto, requereria um tratamento fiscal não excepcional mas próprio e diferenciado.

Finalmente, consideramos que tanto a posição da Comissão como do TJUE é ambígua no que diz respeito a saber se o regime fiscal das cooperativas deve ser olhado como um regime privilegiado, com a natureza de benefício fiscal, através do qual o Estado compensa as cooperativas pelos custos próprios da sua função social, ou se, pelo contrário, deve ser considerado na perspectiva de um regime fiscal autónomo, não privilegiado, justificado pelas características próprias das cooperativa.

\section{Bibliografia}

AGUSTÍN ROMERO CIVERA, A., 2010. "La fiscalidad aplicada a cooperativas en Europa y la reforma del régimen fiscal en España», CIRIEC-España, Revista de Economía Pública, Social y Cooperativa, n. ${ }^{\circ} 69,91-118$.

ANDREA BIONDI E MARTIN FARLEY, 2011. "The relationship between the state aid and the single market», em Research Handbook on European State Aid Law, ed. por Erika Szyszczak (Temple: Edward Elgar Publishing), 277-290.

ANDREA BIONDI, 2006. «Some reflections on the notion of «state resources» in European Community state aid law», Fordham International Law Journal, vol. 30, n. ${ }^{\circ}$ 5, p. 1426-1448.

CHRISTIAN AHLBORN e CLAUDIA BERG, 2004. "Can aid state control learn from antitrust? The need for a greater role for competition analysis under the sate aid rules», em The Law of State Aid in the European Union, ed. por Andrea Biondi, Piet Eeckhout, and James Flynn (Oxford: Oxford University Press).

CLAIRE MICHEAU, 2011. "State aid and taxation in European Union Law», em Research Handbook on European State Aid Law, ed. por Erika Szyszczak, (Cheltenham : Edward Elgar Publishing), 193-217.

DANIELE FRESCURATO, 2015. "State aid issues in VAT and direct taxation», em Global Trends in VAT/GST and Direct Taxation, ed. por Sebastian Pfeiffer, Marlies Ursprung-Steindl (Viena: Linde), 679-707.

DEOLINDA APARICIO, 2015. "O regime de distribuição de resultados nas cooperativas de crédito em Portugal. Uma análise crítica». Boletín de la Asociación Internacional de Derecho Cooperativo 49: 83-113. 
DEOLINDA APARÍCIO, 2013. "O regime jurídico do excedente cooperativo. Anotação ao acórdão do supremo tribunal de justiça, de 17 de Outubro de 2002», RIDB n. ${ }^{\circ} 3$, pp. 2103-2123.

DEOLINDA APARÍCIO, 2012. "Revisitando o problema da distinção entre excedente cooperativo e lucro societário», em Actas do /I Congresso Direito das Sociedades em Revista, (Coimbra: Almedina), pp. 353-374.

EMMANUELE CUSA, 2013. "State aid law and cooperatives in Europe», em Genossenschaften im Fokus einer neuen Wirtschaftspolitik: Bericht der XVII. Internationalen Genossenschaftswissenschaftlichen Tagung (IGT) 2012 in Wien, Parte 1, ed. por Johann Brazda, Markus Dellinger e Dietmar Rossl (Munique:LIT), 1005-1119.

FRANCESCO DE CECCO, 2012. State Aid and the European Economic Constitution (Londres: Bloomsbury Publishing).

ISAAC MERINO JARA, 2010. "El régimen fiscal de las cooperativas irespeta el régimen comunitario de ayudas de estado?», GEZKI-Revista Vasca de Economía Social, n. ${ }^{\circ}$ 6, 29-57.

ISAAC MERINO JARA, 2009. «El vigente régimen fiscal de las cooperativas a la luz de las ayudas de Estado», CIRIEC-España, Revista de Economía Pública, Social y Cooperativa, n. ${ }^{\circ} 66,109-126$.

JOSÉ MANUEL TEJERIZO LÓPEZ, 2010. «Algunas reflexiones sobre el régimen fiscal de las cooperativas», CIRIEC-España, Revista de Economía Pública, Social y Cooperativa, n. ${ }^{\circ} 69,53-72$.

JUAN JORGE PIERNAS LÓPEZ, 2015. The Concept of State Aid Under EU Law: From internal market to competition and beyond (Oxford: Oxford University Press).

JUAN JOSÉ HINOJOSA TORRALVO, 2010. «Fiscalidad y financiación de las cooperativas: ¿a qué juega la Unión Europea?», CIRIEC-España, Revista de Economía Pública, Social y Cooperativa, n. ${ }^{\circ}$ 69: 73-89.

LEIGH HANCHER, Tom Ottervanger e Piet Jan Slot. 2012. EU State Aids (Londres: Sweet \& Maxwell).

LUÍS CABRAL DE MONCADA, 1995. Lições de Direito Civil, 4. ${ }^{a}$ ed. (Coimbra: Almedina).

MAGNUS SCHMAUCH, 2013. EU Law on State Aid on Airlines: Law, Economics and Policy (Berlim: Lexxion Verlagsgesellschaft).

MANUEL PANIAGUA ZURERA, 2005. "La determinación y la distribución de los resultados del ejercicio económico en la Sociedad cooperativa: propuestas de armonización legislativa», em Revista de derecho de sociedades, n. ${ }^{\circ} 24$, 199-229.

MARCO ANTONIO RODRIGO RUIZ, 2010. "Consideraciones sobre el régimen fiscal de las cooperativas. Problemas actuales y líneas de reforma», CIRIECEspaña, Revista de Economía Pública, Social y Cooperativa, n. ${ }^{\circ}$ 69, 9-25.

MARIA PILAR ALGUACIL, 2010. "Condicionantes el régimen de ayudas de estado en la fiscalidade de cooperativas», CIRIEC-España, Revista de Economía Pública, Social y Cooperativa, n. ${ }^{\circ} 69,27-52$.

MARIA PILAR ALGUACIL, 2013. "Tax treatment of cooperatives in Europe under state aid rules», em Genossenschaften im Fokus einer neuen 
Wirtschaftspolitik: Bericht der XVII. Internationalen Genossenschaftswissenschaftlichen Tagung (IGT) 2012 in Wien, Parte 1, ed. por Johann Brazda, Markus Dellinger e Dietmar Rossl (Munique:LIT), 1091-1104.

MARIE-ANN KRONTHALER e YINON TZUBERY, 2015. "The state aid provisions of the TFEU in tax matters», em Introduction to European Tax Law on Direct Taxation, ed. por Michael Lang, Pasquale Pistone, Josef Schuch e Claus Staringer (Viena: Linde Verlag), 95-130.

MICHAEL SCHÜTTE, 2006 «The notion of state aid», em The EC State Aid Regime: Distortive Effects of State Aid on Competition Trade, ed. por Michael Sanchez Rydelski (Londres: Cameron May), 23-53.

MIKEL AZCOAGA IBARRA, 2014. «Tax treatment of cooperatives and EU State aid policy», Revista Vasca de Economía Social, n. ${ }^{\circ} 11,103-142$.

NINA AGUIAR, 2013/2014. "A tributação do rendimento das cooperativas em Portugal», RCES-Revista Cooperativismo y Economía Social, n. ${ }^{\circ} 36,55-80$.

NINA AGUIAR, 2015. "Princípios cooperativos e benefícios fiscais», CIRIEC-España, Revista Jurídica de Economia Social e Cooperativa, n. ${ }^{\circ} 27,429-458$.

PHEDON NICOLAIDES, MIHALIS KEKELEKIS e PHILIP BUYSKES, 2005. State Aid Policy in the European Community: A Guide for Practitioners (Kluwer Law International).

PIERPAOLO ROSSI MACCANICO, 2009. "The Point on selectivity in state aid review of business tax measures», em Legal Remedies in European Tax Law, ed. por Sebastian Pfeiffer e Marlies Ursprung-Steindl (Amesterdão: IBFD), 223-234.

ROBERT SCHÜTZE, 2015. An Introduction to European Law (Cambridge: Cambridge University Press).

SOFÍA ARANA LANDÍN, 2011. "El régimen fiscal de las cooperativas españolas en la Unión Europea: conclusiones para las líneas de reforma del cooperativismo español», GEZKI-Revista Vasca de Economía Social, n. ${ }^{\circ} 7$, 77-98.

VITTORIO DI BUCCI, 2006. «Direct taxation - State aid in form of fiscal measures», em The EC State Aid Regime: Distortive Effects of State Aid on Competition Trade, ed. por Michael Sánchez Rydelski, (Londres: Cameron May), 73-90. 


\section{Derechos de autor}

El Boletín de la Asociación Internacional de Derecho Cooperativo es una revista de acceso abierto lo que significa que es de libre acceso en su integridad inmediatamente después de la publicación de cada número. Se permite su lectura, la búsqueda, descarga, distribución y reutilización legal en cualquier tipo de soporte sólo para fines no comerciales y según lo previsto por la ley; sin la previa autorización de la Editorial (Universidad de Deusto) o el autor, siempre que la obra original sea debidamente citada (número, año, páginas y DOI si procede) y cualquier cambio en el original esté claramente indicado.

\section{Copyright}

The International Association of Cooperative Law Journal is an Open Access journal which means that it is free for full and immediate access, reading, search, download, distribution, and lawful reuse in any medium only for non-commercial purposes, without prior permission from the Publisher or the author; provided the original work is properly cited and any changes to the original are clearly indicated. 